\title{
About the temperature of polymorphic phase transformation of austenite into ferrite of $12 \%$ chromium steel
}

\author{
E. K. Nesterenko ${ }^{\dagger}$, A. S. Kudryavtsev, A. Yu. Askinazi, N. B. Gromova, N. F. Drozdova \\ †nesterenko_ekaterinaekn@mail.ru
}

NRC "Kurchatov institute” — CRISM “Prometey”, 49 Shpalernaya St., St. Petersburg, 191015, Russia

\begin{abstract}
Determining the temperature of the polymorphic phase transformation of austenite into $\delta$-ferrite $\left(\mathrm{Ac}_{4}\right)$ is of great practical importance for ensuring deformability during hot plastic deformation of high-chromium martensitic and martensitic-ferrite steels, as it allows to exclude the formation of cracks in the steel billet during deformation. By limiting the heating temperature for hot plastic deformation, it is possible to prevent the segregation of $\delta$-ferrite, the formation of which leads to the appearance of cracks along the boundaries of its section with austenite. In this article, the temperature of phase transformation was determined for the steel grade $07-\mathrm{Cr} 12-\mathrm{Ni}-\mathrm{Mo}-\mathrm{V}-\mathrm{Nb}$ martensitic ferritic class. Three industrial smelting with different content of alloying elements within the steel grade composition were investigated. $\mathrm{Ac}_{4}$ temperature was determined by differential scanning calorimetry (DSC), X-ray phase analysis and dilatometric method. Dilatometric and DSC studies were conducted under the same heating rate and showed similar results in the temperature range $1155-1181^{\circ} \mathrm{C}$ for all smelting. The temperature of transformation of austenite into $\delta$-ferrite under continuous heating is identified more clearly as a result of measuring the heat flow of the DSC method than by measuring the elongation of the sample by the dilatometric method. $\mathrm{X}$-ray phase analysis showed lower temperature values $<1150^{\circ} \mathrm{C}$, however, they can be considered the most accurate, since this method is a direct method for determining the phase composition of materials due to the comparability of the wavelength of the X-ray radiation and the size of the crystal lattice, thereby obtaining diffraction reflections not from atoms, but from different planes of the crystal lattices. The increased values of DSC and the dilatometric method are associated with continuous heating, during which the fixation of the phase transformation temperature occurs in the presence of a certain content of the new phase. Thus, as a result of research it is established that the temperature of heating for hot plastic deformation should not exceed the temperature of $1150^{\circ} \mathrm{C}$.
\end{abstract}

Keywords: corrosion-resistant steel, martensitic-ferritic steel, $\delta$-ferrite, heating temperature for hot plastic deformation.

УДК: 620.181

\section{О температуре полиморфного фазового превращения аустенита в $\delta$-феррит $12 \%$-ной хромистой стали}

\author{
Нестеренко Е.К.†, Кудрявцев А. С., Аскинази А. Ю., Громова Н. Б., Дроздова Н. Ф. \\ НИЦ «Курчатовский институт» - ЦНИИ КМ «Прометей», ул. Шпалерная 49, С.-Петербург, 191015, Россия
}

\begin{abstract}
Определение температуры полиморфного фазового превращения аустенита в $\delta$-феррит (Ас 4 ) имеет большое практическое значение для обеспечения деформируемости при горячем переделе высокохромистых мартенситных и мартенситно-ферритных сталей, поскольку позволяет исключить образование трещин в заготовках в процессе деформации. За счет ограничения температуры нагрева под горячую пластическую деформацию можно предотвратить выделение $\delta$-феррита, образование которого приводит к появлению трещин по границам его раздела с аустенитом. В настоящей работе температура фазового превращения определялась для стали марки 07Х12НМФБ мартенситно-ферритного класса. Исследованы три промышленные плавки с разным содержанием легирующих элементов в пределах марочного состава. Температура Ас 4 определялась с помощью дифференциальной сканирующей калориметрии (ДСК), рентгеноструктурного фазового анализа и дилатометрического метода. Дилатометрические и ДСК исследования проводились в условиях одинаковой скорости нагрева и показали близкие
\end{abstract}


результаты в диапазоне температур $1155-1181^{\circ} \mathrm{C}$ для всех плавок. Температура превращения аустенита в $\delta$-феррит при непрерывном нагреве фиксируется более отчетливо в результате измерения теплового потока ДСК методом, чем измерением удлинения образца дилатометрическим методом. Рентгеноструктурный фазовый анализ показал более низкие значения температуры $<1150^{\circ} \mathrm{C}$, тем не менее их можно считать наиболее точными, так как данный метод является прямым методом определения фазового состава материалов вследствие сопоставимости длины волны рентгеновского излучения и размеров кристаллической решетки, за счет чего получаются дифракционные отражения не от атомов, а от различных плоскостей кристаллических решеток. Повышенные значения ДСК и дилатометрического метода связаны с непрерывным нагревом, в ходе которого фиксация температуры фазового превращения происходит при наличии уже некоторого содержания новой фазы. Таким образом, в результате работы установлено, что температура нагрева под горячий пластический передел не должна превышать температуру $1150^{\circ} \mathrm{C}$.

Ключевые слова: коррозионно-стойкая сталь, мартенситно-ферритная сталь, $\delta$-феррит, температура нагрева под горячую пластическую деформацию.

\section{1. Введение}

Для парогенератора реакторной установки большой мощности с натриевым теплоносителем специалистами НИЦ «Курчатовский институт» - ЦНИИ КМ «Прометей» разработана сталь марки 07Х12НМФБ мартенситно-ферритного класса $[1,2]$.

Сталь обладает высоким уровнем служебных свойств, необходимых для материала парогенератора [2-5], однако не является высокотехнологичным материалом. Так, в процессе горячей пластической деформации может иметь место образование трещин, связанных с падением пластичности стали в результате выделения $\delta$-феррита при сравнительно невысоком уровне температуры нагрева [6]. В процессе пластической деформации двухфазной стали феррит подвергается более значительным локальным деформациям и перенапряжениям, чем аустенит и, несмотря на более высокую пластичность по ферриту, избирательно происходит нарушение сплошности деформируемого тела [7-9].

Таким образом, температурный режим нагрева под горячий пластический передел должен обеспечить формирование в стали однофазной структуры, что обеспечит высокий уровень пластичности. То есть, температура не должна превышать температуру $\mathrm{Ac}_{4}$ - температуру фазового превращения аустенита в $\delta$-феррит.

Цель настоящей работы - определение допустимой температуры нагрева под горячую пластическую деформацию стали марки 07Х12НМФБ, путем определения температуры начала фазового превращения аустенита в $\delta$-феррит (критической точки $\mathrm{Ac}_{4}$ ).

\section{2. Материал и методика проведения исследования}

Исследование выполнено на стали марки 07Х12НМФБ трёх плавок, химический состав которых представлен в Табл. 1.

Выплавка и разливка стали марки 07Х12НМФБ (плавка 1 и 2) проводилась на ООО «ОМЗ-Спецсталь» (г. Колпино, г. Санкт-Петербург) в 50 т дуговой электропечи с последующим рафинированием и вакуумированием металла на установке внепечного рафинирования и вакуумирования (УВРВ).

Плавка 3, стали марки 07Х12НМФБ, выплавлена на ОАО «МЕЧЕЛ» (г. Челябинск) в вакуумной индукционной печи с разливкой в слиток массой 0.5 т.

Для определения температуры начала фазового превращения аустенита в $\delta$-феррит в стали марки 07Х12НМФБ использовались следующие методы измерений:

- дилатометрический;

- дифференциальная сканирующая калориметрия (ДСК);

- рентгеноструктурный фазовый анализ.

Подобный комплексный подход, использующий современные методы изучения структуры и фазовых превращений в стали, является гарантией получения достоверных результатов и широко используется различными авторами [10].

Дилатометрические исследования проводились на дилатометре DIL 805 фирмы BAHR Thermoanalise (Германия) на цилиндрических образцах $\varnothing 5 \times 10$ мм по режиму: нагрев от комнатной температуры до $1250^{\circ} \mathrm{C}$

Табл. 1. Химический состав исследованных плавок стали марки 07Х12НМФБ (основные легирующие элементы).

Table 1. The chemical composition of the studied melting of steel grade $07 \mathrm{Cr} 12 \mathrm{NbMoVNb}$ (basic alloying elements).

\begin{tabular}{|c|c|c|c|c|c|c|c|c|c|c|c|}
\hline \multirow{2}{*}{$\begin{array}{c}\text { № плавки } \\
\text { №. melting }\end{array}$} & \multicolumn{11}{|c|}{$\begin{array}{c}\text { Содержание химических элементов, мас.\% } \\
\text { Content of chemical elements, wt.\% }\end{array}$} \\
\hline & C & $\mathrm{Mn}$ & Si & $\mathrm{Cr}$ & $\mathrm{Ni}$ & Mo & V & $\mathrm{N}$ & $\mathrm{Al}$ & $\mathrm{Nb}$ & $\begin{array}{c}\text { В } \\
\text { (по рассчету) } \\
\text { (by calculation) }\end{array}$ \\
\hline 1 & 0.05 & 0.73 & 0.12 & 12.40 & 0.96 & 0.95 & 0.20 & 0.060 & 0.05 & 0.12 & - \\
\hline 2 & 0.08 & 0.07 & 0.29 & 12.10 & 1.06 & 0.94 & 0.20 & 0.059 & 0.029 & 0.11 & 0.003 \\
\hline 3 & 0.08 & 0.71 & 0.27 & 11.90 & 0.98 & 0.89 & 0.20 & 0.043 & 0.04 & 0.11 & 0.005 \\
\hline
\end{tabular}


со скоростью $10^{\circ} \mathrm{C} /$ мин. При испытаниях регистрируется удлинение образца в зависимости от температуры и времени. Положение температур фазовых и структурных превращений определяют методом касательной при отклонении от монотонного хода кривой теплового расширения. Отклонения от прямой на кривой расширения (перегибы) - соответствуют температурам фазовых и структурных превращений [11].

Исследование методом дифференциальной сканирующей калориметрии выполнено на приборе синхронного термического анализа STA 449F1 фирмы Netzsch (Германия) на образцах в виде дисков $\varnothing 5 \times 2$ мм по режиму: нагрев от комнатной температуры до $1250^{\circ} \mathrm{C}$ со скоростью $10^{\circ} \mathrm{C} /$ мин. За температуру начала фазового превращения принималась точка экстраполированного начала теплового пика, которой соответствует температура максимума второй производной ДСК-кривой, а в качестве температуры окончания стадии превращения - температура максимума первой производной ДСК-сигнала по времени [12,13].

Рентгеноструктурный фазовый анализ выполнен на многофункциональном рентгеновском дифрактометре ULTIMA IY фирмы Rigaku Corporation на образце в виде прямоугольной пластины высотой 1 мм, длиной 25 мм, шириной 10 мм. Рентгенографирование осуществлялось в фильтрованном $\mathrm{Cu}_{\mathrm{Ka}}$-излучении с режимом работы рентгеновской трубки 40 кВ и 40 мА, шагом перемещения сцинтилляционного детектора $0.02^{\circ}$ и экспозицией в точке 2 или 3 секунды в зависимости от интенсивности исследуемых дифракционных отражений. Коллимация первичного и дифрагированного рентгеновских пучков осуществлялась с помощью щелей: DivSlit $=2 / 3^{\circ}$, DivH.L.Slit $=10$ мм, SctSlit $=2 / 3^{\circ}$, RecSlit $=0.3$ мм. Исследование фазовых превращений в образце стали марки 07Х12НМФБ проводилось в диапазоне температур от $700-1250^{\circ} \mathrm{C}$.

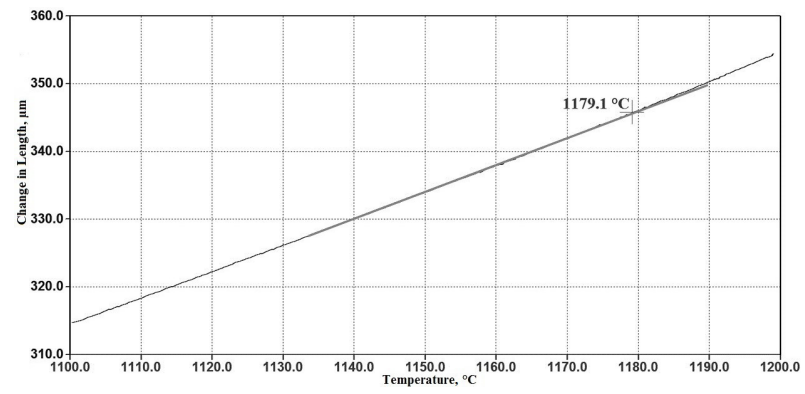

a

\section{3. Основные результаты выполненных исследований и их обсуждение}

Результаты определения температуры фазового превращения $\mathrm{Ac}_{4}$ стали марки 07Х12НМФБ методом дилатометрического анализа представлены на Рис. 1 и в Табл. 2.

Полученные значения $\mathrm{Ac}_{4}$ достаточно близки. Разброс составляет порядка $25^{\circ} \mathrm{C}(\approx 2 \%)$, разница обусловлена изменением температур фазовых превращений в стали в зависимости от соотношения аустенито- и ферритостабилизирующих элементов [6,14]. Увеличение доли аустенито-стабилизирующих элементов (C, N, Ni, Mn, Cu), расширяет область $\gamma$-твердого раствора, сдвигает температуру $\mathrm{Ac}_{4}$ в область более высоких значений [15 -17].

Следует отметить, что отклонение дилатометрической кривой от линейности, обусловленное фазовым превращением $\mathrm{Ac}_{4}$ - очень плавное и незначительное, что затрудняет определение температуры. В данном случае, вероятно, точность определения может быть повышена за счет цифровой обработки результатов [18].

Значения $\mathrm{Ac}_{4}$, полученные методом дифференциальной сканирующей калориметрии (Рис. 2, Табл. 2) близки к значениям полученным методом дилатометрии, разница для каждой плавки не превышает 3 С ( $\approx 0.25 \%)$,

Табл. 2. Температура фазового превращения при различных методах.

Table 2. Phase transformation temperature at different methods.

\begin{tabular}{|c|c|c|}
\hline \multirow{2}{*}{$\begin{array}{c}\text { № плавки } \\
\text { N melting }\end{array}$} & $\begin{array}{c}\text { Дилатометрический анализ } \\
\text { Dilatometric analysis }\end{array}$ & $\begin{array}{c}\text { ДСК } \\
\text { DSC }\end{array}$ \\
\hline 1 & $\begin{array}{c}\text { Температура фазового превращения } \mathrm{Ac}_{4}{ }^{\circ}{ }^{\circ} \mathrm{C} \\
\text { Phase transformation temperature } \mathrm{Ac}_{4},{ }^{\circ} \mathrm{C}\end{array}$ \\
\hline 2 & 1179 & 1181 \\
\hline 3 & 1171 & 1168 \\
\hline \multicolumn{2}{|c|}{} \\
\hline
\end{tabular}

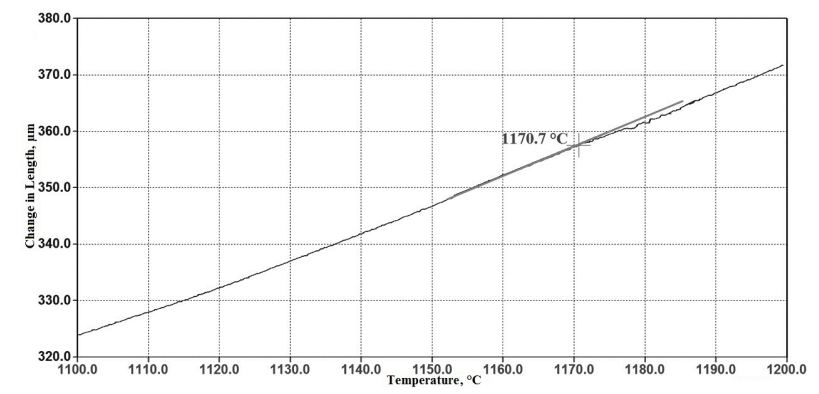

$\mathrm{b}$

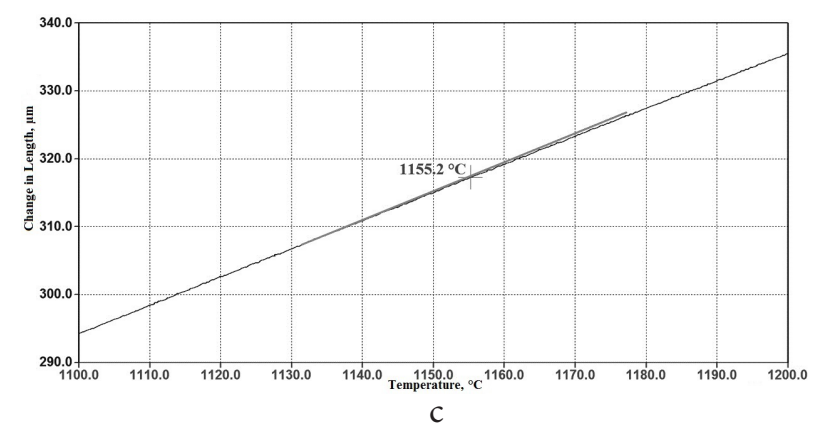

Рис. 1. Дилатометрические кривые нагрева до температуры $1250^{\circ} \mathrm{C}$ со скоростью $10^{\circ} \mathrm{C} /$ мин: плавка 1 (a); плавка 2 (b); плавка 3 (c).

Fig. 1. Dilatometric curves of heating to a temperature of $1250^{\circ} \mathrm{C}$ at a rate of $10^{\circ} \mathrm{C} / \mathrm{min}$ : melting 1 (a); melting 2 (b); melting 3 (c). 


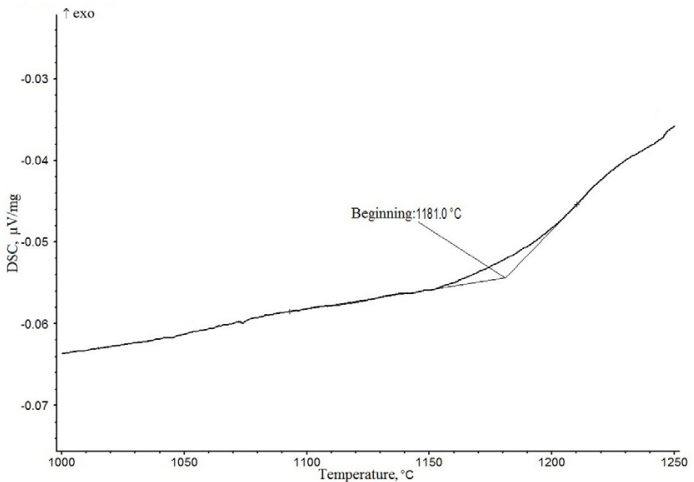

a

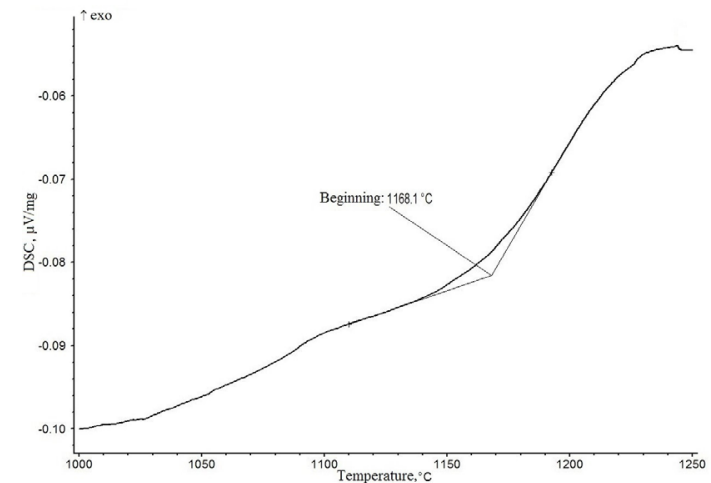

b

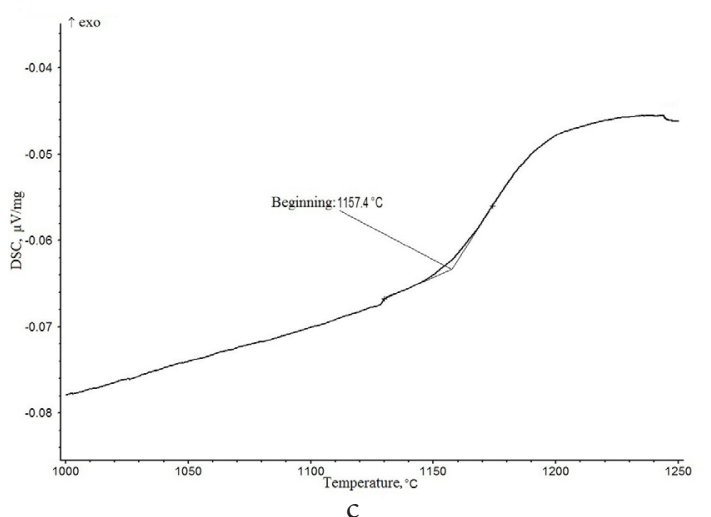

Рис. 2. Термограммы для стали марки 07Х12НМФБ, скорость нагрева $10^{\circ} \mathrm{C} /$ мин: плавка 1 (a); плавка 2 (b); плавка 3 (c). Fig. 2. Thermograms for steel grades $07-\mathrm{Cr} 12-\mathrm{Ni}-\mathrm{Mo}-\mathrm{V}-\mathrm{Nb}$, heating rate $10^{\circ} \mathrm{C} / \mathrm{min}$ : melting 1 (a); melting 2 (b); melting 3 (c).

что говорит о достаточно высокой точности определения температуры фазового превращения и о взаимозаменяемости методов.

Однако в целом точка фазового превращения $\mathrm{Ac}_{4}$ фиксируется на кривой ДСК отчетливее.

Рентгеноструктурный фазовый анализ проводился на образце плавки 1 стали марки 07Х12НМФБ. Прецизионные съемки проводились в интервале брэгговских углов дифракции, в котором присутствуют дифракционные отражения с максимальной интенсивностью следующих фаз: от серии плоскостей (110) ОЦК решетки (пространственная группа Im $3 \mathrm{~m}$ ), соответствующей $\alpha-\mathrm{Fe}$ (феррит) и $\delta$-Fe ( $\delta$-феррит) и от серии плоскостей (111) ГЦК решетки (пространственная группа Fm3m), соответствующей $\gamma$-Fe (аустенит). По данным отражениям определялся фазовый состав и процентное содержание присутствующих фаз.

Для определения параметров кристаллических решеток, образующихся при различных температурах, проводились съемки дифракционных максимумов от серии плоскостей (220) ОЦК решетки (пространственная группа $\mathrm{Im} 3 \mathrm{~m})$, соответствующей $\alpha$-Fe (феррит) и $\delta$-Fe ( $\delta$-феррит) и от серии плоскостей (222) ГЦК решетки (пространственная группа Fm3m), соответствующей $\gamma$-Fe (аустенит).

В соответствии с полученными данными (Табл. 3) при температуре $1150^{\circ} \mathrm{C}$ в стали присутствует $\delta$-феррит, причем его количество составляет более $4 \%$, то есть его выделение произошло при температуре менее $1150^{\circ} \mathrm{C}$.
Табл. 3. Результаты рентгеноструктурного исследования. Table 3. Results of X-ray diffraction study.

\begin{tabular}{|c|c|c|c|c|}
\hline \multirow{2}{*}{$\begin{array}{c}\text { Tемпература, }{ }^{\circ} \mathrm{C} \\
\text { Temperature, }{ }^{\circ} \mathrm{C}\end{array}$} & $\begin{array}{c}\text { Количество, \% } \\
\text { Amount, \% }\end{array}$ & $\begin{array}{c}\text { Параметр решетки, } \\
\text { Lattice parameter, } \AA\end{array}$ \\
\cline { 2 - 5 } & \multicolumn{4}{|c|}{$\begin{array}{r}\text { Пространственная группа } \\
\text { Space group }\end{array}$} \\
\cline { 2 - 5 } & Im3m & Fm3m & Im3m & Fm3m \\
\hline 900 & 19 & 81 & 2.907 & 3.651 \\
\hline 950 & 0 & 100 & - & 3.656 \\
\hline 1000 & 0 & 100 & - & 3.658 \\
\hline 1050 & 0 & 100 & - & 3.662 \\
\hline 1100 & 0 & 100 & - & 3.665 \\
\hline 1150 & 4 & 96 & 2.924 & 3.669 \\
\hline 1200 & 6 & 94 & 2.925 & 3.674 \\
\hline 1250 & 1 & 99 & 2.930 & 3.679 \\
\hline
\end{tabular}

Результаты рентгеноструктурного фазового анализа отличаются от результатов дилатометрического анализа и дифференциальной сканирующей калориметрии, которые дают более высокие значения температуры фазового превращения $\left(\mathrm{Ac}_{4}\right)$. При этом, рентгеноструктурный фазовый анализ, являясь прямым методом определения фаз, дает более точные результаты температуры фазовых превращений.

По-видимому, и дилатометрический анализ, и дифференциальная сканирующая калориметрия фиксируют фазовые превращения с неким температурным гистерезисом, связанным с непрерывным нагревом, 


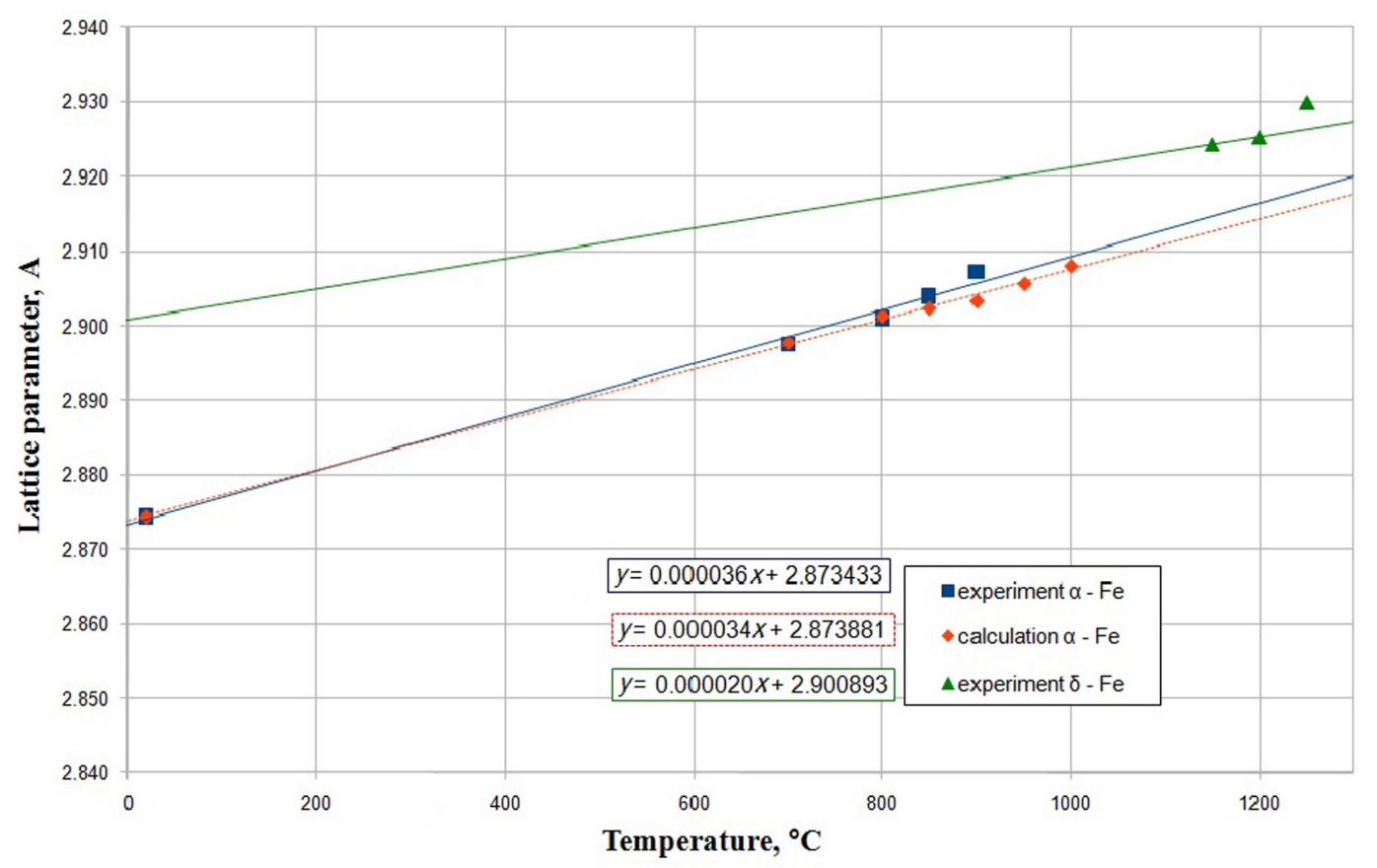

Pис. 3. (Color online) Зависимость параметра кристаллической решетки $\alpha$-Fe, расчетная и экспериментальная, и $\delta$-Fе, экспериментальная от температуры исследования.

Fig. 3. (Color online) Dependence of the crystal lattice parameter of $\alpha$-Fe, calculated and experimental, and $\delta$-Fe experimental, from temperature.

а также при наличии уже некоторого содержания новой фазы в момент регистрации отклонения.

На Рис. 3 представлена зависимость параметра кристаллической решетки $\alpha-\mathrm{Fe}$, расчетная и экспериментальная, и $\delta$-Fe, экспериментальная, от температуры исследования. Отличие расчетной кривой линейного расширения параметра кристаллической решетки $\alpha-\mathrm{Fe}$ от экспериментальных значений не превышает $5 \%$. На графике видно явное отличие параметра кристаллической ОЦК решетки до $900^{\circ} \mathrm{C}$ и после $1150^{\circ} \mathrm{C}$, что свидетельствует о том, что фаза при температуре выше $1150^{\circ} \mathrm{C}$ является высокотемпературной аллотропной модификацией железа, $\delta$-ферритом. Таким образом, с целью исключения в структуре стали марки 07Х12НМФБ $\delta$-феррита в процессе горячей пластической деформации температура нагрева не должна превышать $1150^{\circ} \mathrm{C}$.

\section{4. Выводы}

На основании проведенных исследований установлено:

Методы дилатометрического анализа и дифференциальная сканирующая калориметрия дают близкие значения $\mathrm{Ac}_{4}$ стали марки 07Х12НМФБ в диапазоне $1155-1179^{\circ} \mathrm{C}$. При этом на кривых дифференциальной сканирующей калориметрии фазовое превращение аустенита в $\delta$-феррит наблюдается более четко.

Полученные значения дилатометрического анализа и дифференциальной сканирующей калориметрии несколько завышены, о чем свидетельствует наличие в структуре стали $\delta$-феррита в количестве $4 \%$ уже при температуре $1150^{\circ} \mathrm{C}$ по данным рентгеноструктурного анализа.
Анализ полученных тремя независимыми методами значений температуры фазового превращения определяет, что температура нагрева под горячую пластическую деформацию стали марки 07Х12НМФБ не должна превышать $1150^{\circ} \mathrm{C}$.

Благодарности/Aknowledgements. Экспериментальные исследования выполнень на оборудовании Центра коллективного пользования научным оборудованием «Состав, структура и свойства конструкиионных и функииональных материалов» НИЦ «Курчатовский институт» - ЦНИИ КМ «Прометей» при финансовой поддержке государства в тиие Минобрнауки в рамках соглашения № 14.595.21.0004, уникальный идентификатор RFMEFI59517X0004. / Experimental studies were performed on the equipment of the Center for the collective use of scientific equipment "Composition, structure and properties of constructional and functional materials" NRC "Kurchatov Institute" - Central Research Institute of SM "Prometey" with financial support from the state represented by the Ministry of Education and Science in the framework of agreement No. 14.595.21.0004, unique identifier RFMEFI59517X0004.

\section{Литература}

1. Patent RF № 2013127543/02, 17.06.2013. (in Russian) [Патент РФ № 2013127543/02, 17.06.2013].

2. S.L. Lyakishev, V.V. Denisov, M.D. Lyakisheva, V.A. Chaban, A.A. Khalutin, A.N. Blokhina, N.V. Zharov, V.A. Usachev. Problems of atomic science and technology. 34, 113 (2014). (in Russian) [С.Л. Лякишев, В.В. Денисов, М.Л. Лякишева, 
В. А. Чабан, А. А. Халутин, А. Н. Блохина, Н. В. Жаров, В.А. Усачев. Вопросы атомной науки и техники. 34 , 113 (2014).]

3. G.P. Karzov, A.S. Kudriavtsev, V. G. Markov, R. N. Grishmanovskaya, Yu.M. Trapeznikov, M.A. Ananieva. Voprosy Materialovedeniya. 2 (82), 23 (2015). (in Russian) [Г.П. Карзов, А.С. Кудрявцев, В.Г. Марков, Р.Н. Гришмановская, Ю. М. Трапезников, М. А. Ананьева. Вопросы материаловедения. 2 (82), 23 (2015).]

4. D.A. Artemieva, G.P. Karzov, A.S. Kudriavtsev, V.G. Markov, S.A. Suvorov, S.I. Brykov, V.V. Denisov, S. Yu. Korolev, M.S. Metalnikov. Problems of atomic science and technology. 34, 53 (2014). (in Russian) [Д.А. Артемьева, Г.П. Карзов, А.С. Кудрявцев, В. Г. Марков, С. А. Суворов, С. И. Брыков, В. В. Денисов, С. Ю. Королев, М.С. Метальников. Вопросы атомной науки и техники. 34, 53 (2014).]

5. R.L. Klueh, A.T. Nelson. Journal of Nuclear Materials. 371, 37 (2007). Crossref

6. A.S. Kudriavtsev, D. A. Artemieva, P. Ya. Rayner. Voprosy Materialovedeniya. 3 (79), 34 (2014). (in Russian) [А.С. Кудрявцев, Д.А. Артемьева, П.Я. Рейнер. Вопросы материаловедения. 3 (79), 34 (2014).]

7. M. Ya. Dzugutov. Plasticheskaya deformatsiya vysokolegirovannykh staley i splavov. Moscow, Metallurgiya (1977) 479 p. (in Russian) [М. Я. Дзугутов. Пластическая деформация высоколегированных сталей и сплавов. Металлургия, Москва (1977) 479 c.]

8. K.A. Lanskaya. Vysokokhromistyye zharoprochnyye stali. Moscow, Metallurgiya (1976) 216 p. (in Russia) [К.А. Ланская. Высокохромистые жаропрочные стали. Москва. Металлургия (1976) 216 с.]

9. E. A. Krivonosova, E. A. Sinkina, O. A. Rudakova. Bulletin of Perm national research Polytechnic University. 13 (1), 32 (2011). (in Russian) [Е.А. Кривоносова, Е.А. Синкина, О.А. Рудакова. Вестник Пермского национального исследовательского политехнического университета. 13 (1), 32 (2011).]
10. L. M. Kaputkina, D.E. Kaputkin. Materials Science Forum. 426-432, 1119 (2003). Crossref

11. P. A. Leont'ev, Yu. N. Simonov, D. O. Panov. Industrial laboratory. Diagnostics of materials. 80 (6), 45 (2014). (in Russian) [П.А. Леонтьев, Ю.Н. Симонов, Д. О. Панов. Заводская лаборатория. Диагностика материалов. 80 (6), 45 (2014).]

12. D.V. Gadeev. Issledovaniye fazovykh prevrashcheniy metodami strukturnogo i termicheskogo analiza $\mathrm{v}$ dvukhfaznykh splavakh na osnove titana. Dissertacija na soiskanie stepeni kandidata tehnicheskih nauk. Ekaterinburg (2012) 171 p. (in Russian) [Д. В. Гадеев Исследование фазовых превращений методами структурного и термического анализа в двухфазных сплавах на основе титана: дисс. канд. техн. наук. Екатеринбург (2012) 171 с.]

13. A.L. Emelina. Differentsial'naya skaniruyushchaya kalorimetriya. Moscow, Moscow State University (2009) 42 p. (in Russian) [А. Л. Емелина. Дифференциальная сканирующая калориметрия. Москва, МГУ (2009) 42 c.]

14. R.L. Klueh, D. R. Harries. High-Chromium Ferritic and Martensitic Steels for Nuclear Applications. West Conshohocken, PA, ASTM International (2001) 228 p. Crossref

15. E. I. Razuvaev, M. M. Bakradze, S. A. Sidorov. Steel. 9, 58 (2016). (in Russian) [Е.И. Разуваев, М. М. Бакрадзе, С. А. Сидоров. Сталь. 9, 58 (2016).]

16. E. N. Kablov, G.S. Krivonogov. Metals. 2, 65 (2002). (in Russian) [Е.Н. Каблов, Г.С. Кривоногов. Металлы. 2, 65 (2002).]

17. L. J. Lieberman, A.V. Baeva. Metal science and metal processing. 6, 2 (1956). (in Russian) [Л.Я. Либерман, А. В. Баева. Металловедение и обработка металлов. 6 , 2 (1956).]

18. I. V. Teplukhina, V.M. Golod, A.S. Tsvetkov. Latters on Materials. 1(8), 37 (2018). (in Russian) [И.В. Теплухина, В. М. Голод, А. С. Цветков. Письма о материалах. 1(8), 37 (2018).] Crossref 